\title{
ROLE OF OCCUPATIONAL HEALTH AND SAFETY
}

\author{
PROGRAM IN IMPROVING KNOWLEDGE
}

\author{
AND PRACTICE AMONG NURSES EXPOSED TO
}

CHEMOTHERAPY AT ZAGAZIG

\section{UNIVERSITY HOSPITALS}

\author{
By \\ Bolbol SA, Hassan AA, El-Naggar SA and Zaitoun MF \\ Department of Community, Environmental and Occupational Medicine, \\ Faculty of Medicine, Zagazig University.
}

\begin{abstract}
Introduction: Many cytotoxic drugs (CDs) are known to be teratogenic and mutagenic to humans. Nurses are the main groups that are exposed to these drugs in hospital setting. Generally, the occupational activities that pose a greatest risk of exposure are the preparation and administration of CDs, cleaning of CDs spills, and handling of patient excreta. Aim of work and Objectives: This study aims to protect nurses from CDs exposure hazards with the following objectives: 1)To determine health hazards of CDs exposures.2)To apply a health education program for improving knowledge and practice of nurses exposed to CDs.3)To evaluate the effect of health education program on improving the knowledge and practice of nurses exposed to CDs. Materials and Methods: An interventional study (health education program) carried on 50 nurses exposed to CDs in oncology units (Pre and post intervention) at Zagazig University Hospitals. All nurses were subjected to a structured questionnaire included questions about: personal and socio-demographic characteristics, occupational history, and knowledge about CDs drugs. A performance checklist was used to assess the practice of nurses. All nurses were subjected to health education program. Results: Improvement in knowledge among the studied nurses was only affected by nurses' job rank as the knowledge of supervisors improved more than the knowledge of staff nurses. The
\end{abstract}


practice of nurses was not affected by socio-demographic characteristics. It also showed that there was a statistical significant improvement of total knowledge and total performance after intervention by health education ( $4.0 \%$ vs. $98.0 \%$ and $4.0 \%$ vs. $56.0 \%$ respectively). Conclusion: The level of knowledge of nurses about CDs was not satisfactory; also there was a significant improvement of knowledge and practices among the studied nurses handling cytotoxic drugs after intervention.

Keywords: Oncology nurses, cytotoxic drugs, Occupational exposure, Knowledge and Practice.

\section{Introduction}

Oncology nurses provide care for cancer patients. They monitor physical conditions and administer CDs and other treatments. Oncology is one of the most challenging fields in nursing and no two days on the job are ever the same. Oncology nursing practice at the generalist level requires a cancer-specific knowledge base and demonstrated clinical expertise in cancer care beyond that acquired in a basic nursing program (Meijster et al., 2006).

Many anti neoplastic drugs are known to be carcinogenic, teratogenic and mutagenic to humans. There is thus a potential occupational exposure risk to CDs. Nurses are among the main groups of professionals that are exposed to these drugs in patient care settings (NIOSH, 2004).

Awareness of toxic effects of cancer chemotherapeutic drugs typically influences treatment plans for patients undergoing cancer therapy to prevent or mitigate adverse outcomes. However, beyond the patient safety concerns arising from the necessary therapeutic use of these drugs, occupational risks to health care workers handling these drugs in the course of their duties still need to be fully addressed (Thomas et al., 2006).

Studies have demonstrated an increase in the potential risks due to occupational exposure to CDs. Despite current work practice guidelines, nurses exposed to hazardous drugs still experience serious side effects that are influenced by: drug handling circumstances (preparation, administration, or disposal), amount of drug prepared, frequency and duration of drug handling, potential for absorption, use of ventilated cabinets, personal protective equipment (PPE) and work practices (Schreiber et al., 2002). Compliance with guidelines for handling CDs has been reported to be sporadic (Chaudhary and Karn, 2012). 


\section{Aim of Work:}

Thus, this study aims to protect nurses from CDs exposure hazards with objectives to (1) Determine health hazards of CDs exposures (2) Apply a health education program for improving knowledge and practice of nurses exposed to CDs (3) Assess the effect of health education program on improving the knowledge and practice of nurses exposed to CDs

\section{Materials and Methods}

Study design: Interventional study was conducted on nurses exposed to CDs in oncology units at Zagazig university hospitals.

Study sample: All nurses working in oncology units equal 60 (medical oncology unit; 22, nuclear therapy unit: 20 and pediatric oncology unit: 18.). Ten nurses were taken in the pilot study to test the questionnaire with the most appropriate terms, it also helped to estimate time needed for data collection. Pilot nurses were excluded from the study. So, our sample size was 50 nurses.

Time of the study: from June 2014 to December 2014.

\section{Study methods:}

I- Data collection: A structured questionnaire (Elshamy et al., 2010; Chaudhary and Karn, 2012) was used to collect information from all participants about the following:

Part one: included questions about personal and socio-demographic data: age, residence, level of education, marital status.

Part two: included questions about occupational history (current and previous occupation, duration of employment in current occupation, number of hours worked/day, attending training programs and organizational aspects, frequency and place of preparing CDs drugs.)

Part three: Present history of health hazards due to exposure to CDs drugs (reproductive hazards, eye Affection, skin and mucous membrane affection, respiratory Hazards, Others)

Part four: knowledge about cytotoxic drugs (types and definition of CDs drugs, mode of exposure of nurses to CDs drugs, health hazards due to exposure to CDs drugs, personal protective equipment, safe precautions during preparation and administration of CDs drugs, safe precautions if contamination occurs in case of spill) 


\section{II- Health education program:}

Objectives: Improve level of knowledge and level of performance of nurses about CDs drugs.

\section{Message:}

Studied nurses were given educational sessions to cover knowledge about (types and definition of CDs drugs, Mode of exposure of nurses to CDs drugs, health hazards due to exposure to CDs drugs, personal protective equipment, safe precautions during preparation and administration of CDs drugs, safe precautions if contamination occur)

\section{Methods:}

We did the performance checklist before the pretest-questionnaire. The message was formulated to cover all information about CDs drugs. In addition, the use of teaching aids, such as explanatory pictures illustrating the personal protective equipment and some methods of safe handling CDs drugs helped to enrich and facilitate the educational process with distribution of these pictures. This message was given after filling the questionnaire (pretest questionnaire).

\section{Place:}

The educational sessions were given at work place to 2 or more accessible nurses together (maximum 5 females in each session due to working circumstances). Total number of sessions was 9 sessions (3 sessions for nurses during morning shift, 3 sessions for nurses during afternoon and the last 3 session for nurses of night shift when they shifted to morning shift).

\section{Time:}

Each educational session lasted for about 20 minutes after filling of the questionnaire (pretest questionnaire). After three weeks, posttest questionnaire (the same as pretest questionnaire) was filled by studied nurses to assess the effectiveness of health education.

\section{The coding system:}

Change of knowledge and performance were divided on base of median to percent of change (percent of change $=$ (post test score-pre test score) / (pre test score) x 100).

Median of change of knowledge $=$ 154.19. So, $<154.19$ inadequate knowledge, $\quad \geq 154.19$ adequate knowledge 
Median of change of performance $=$ 83.33. So, $<83.33$ incorrectly done, $\geq$ 83.33 correctly done.

Coding system of frequency of adequate knowledge and correct performance $\geq 50 \%$ of the correct answers.

\section{Data analysis:}

The collected data were computerized and statistically analyzed using SPSS program (Statistical Package for Social Science) version 16.0. Assessment of change of knowledge and performance after health education was evaluated by McNemar's test for paired data. Relationship between change of either knowledge or performance and role of some socio-demographic or occupational factors was assessed by
Pearson's Chi-square test .Correlation coefficient ( $r$ ) between change of knowledge and change of performance was done by Pearson's correlation. The test results were considered significant when $\mathrm{p}$-value $<0.05$.

Ethical approval: The ethical committee Institutional Review Board (IRB) of the faculty of Medicine, Zagazig University approved the study protocol. Ethical considerations and confidentiality were respected.

Consent: An informed consent was obtained from all participants of this study. The workers were told about the aim of the study, and they were informed that the data would be used for scientific purposes only. The workers were also given the right to refuse or participate in the study. 


\section{Results}

Table 1: frequency distribution of some socio-demographic, occupational characteristics and availability of organizational aspects as reported by studied nurses.

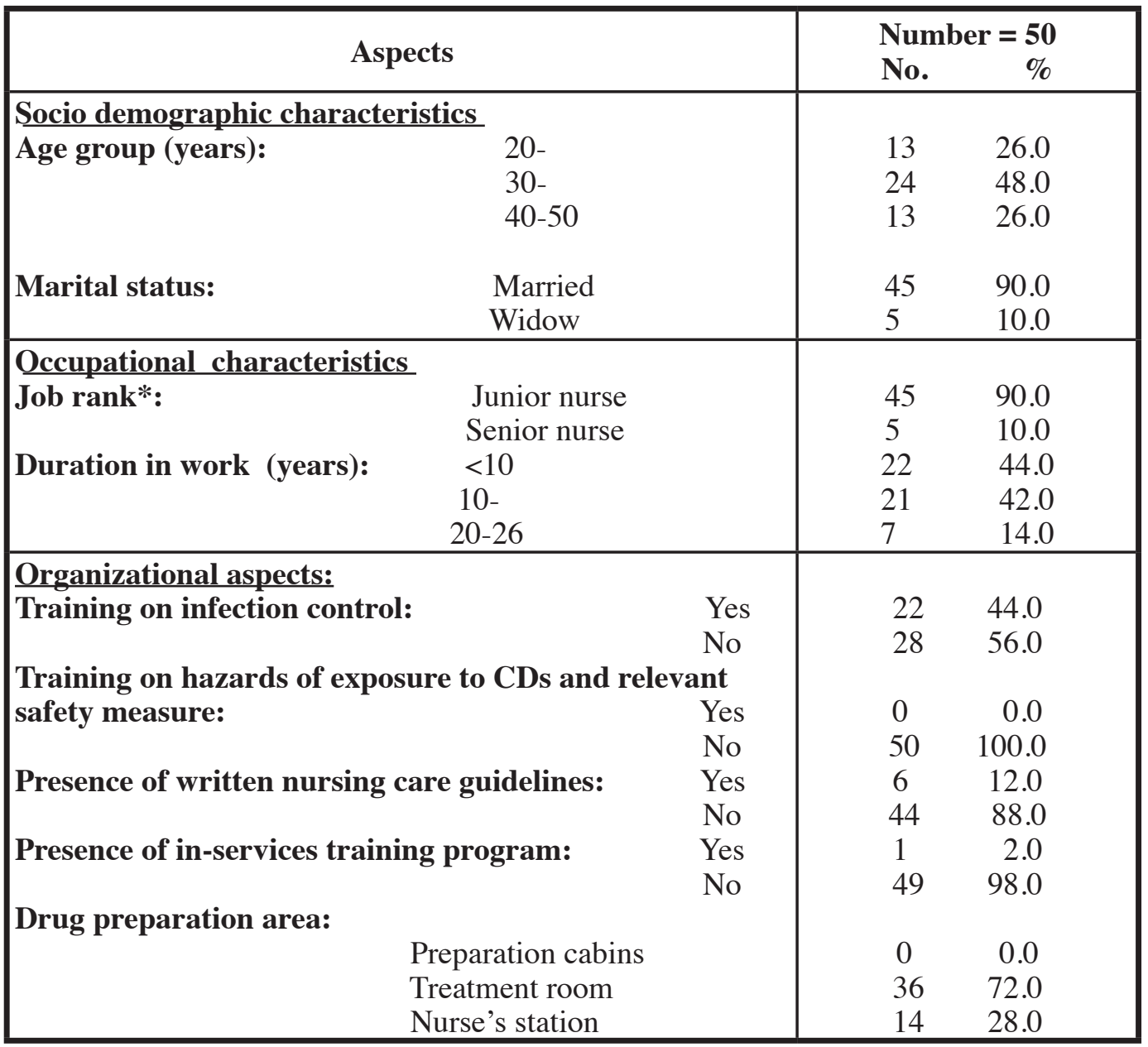

* Classified according to level of education (Juniors 'staff nurses': Diploma and Nursing Institute, Seniors 'supervisors': Faculty of Nursing).

Table 1 shows that (74.0\%) of the studied nurses are above 30 years and (90.0\%) are married, $(44.0 \%)$ of the studied nurses work in the oncology unit for less than 10 years. About (44.0\%) of them attended infection control training course, (72.0\%) reported that they prepare the CDs in treatment room. 


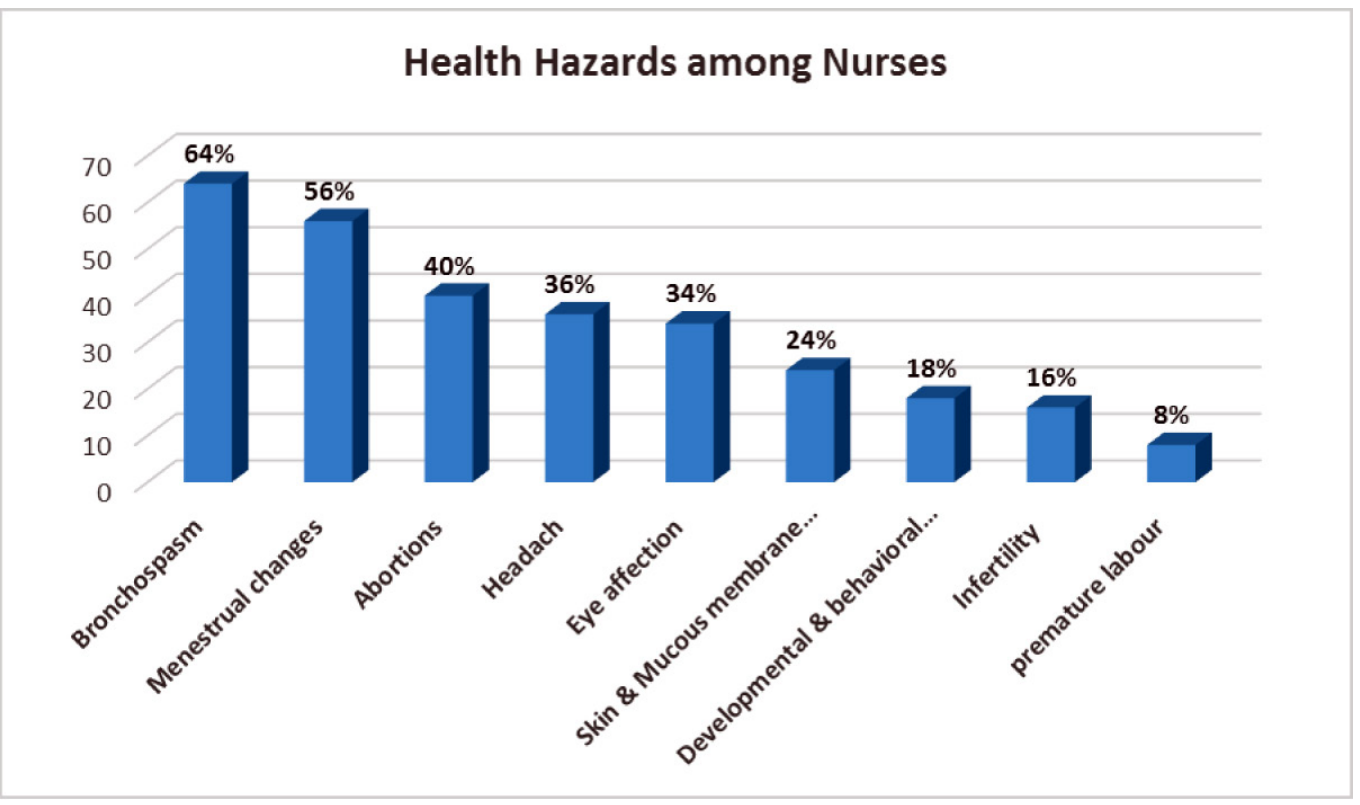

Figure 1: Frequency of Health hazards among studied nurses during exposure

Figure 1 reported health hazards among nurses were bronchospasm (64.0\%), reproductive hazards (such as menstrual changes (56.0\%) and abortions (40.0\%), developmental and behavioral abnormalities among children of nurse $(18.0 \%)$, infertility $(16.0 \%)$ and premature labour $(8.0 \%)$ ), headache (36.0\%), eye affection $(34.0 \%)$, skin \& mucous membrane affection $(24.0 \%)$. 
Table 2: Frequency of correct knowledge about definition of CDs drugs, mode of exposure, risky behaviors and risky practice associated with CDs exposure at pre and post intervention among studied nurses .

\begin{tabular}{|c|c|c|c|c|c|}
\hline Item & \multicolumn{2}{|c|}{$\begin{array}{l}\text { Pre test } \\
\text { No. } \%\end{array}$} & \multicolumn{2}{|c|}{$\begin{array}{l}\text { Post test } \\
\text { No. \% }\end{array}$} & P-value \\
\hline $\begin{array}{l}\text { The definition of CDs drugs } \\
\text { - Wrong answerldon't know } \\
\text { - Incomplete answer } \\
\text { - Complete answer }\end{array}$ & $\begin{array}{l}1 \\
49 \\
0\end{array}$ & $\begin{array}{r}2.0 \\
98.0 \\
0.0\end{array}$ & $\begin{array}{l}0 \\
8 \\
42\end{array}$ & $\begin{array}{r}0.0 \\
16.0 \\
84.0\end{array}$ & $0.000^{*}$ \\
\hline $\begin{array}{l}\text { Mode of exposure: } \\
\text { - Skin } \\
\text { - Injection } \\
\text { - Contaminated food \& drinks } \\
\text { - Handling materials contaminated with } \\
\text { patient excreta } \\
\text { - Inspire aerosol during preparation and } \\
\text { administration }\end{array}$ & $\begin{array}{l}11 \\
19 \\
1 \\
4\end{array}$ & $\begin{array}{r}22.0 \\
38.0 \\
2.0 \\
8.0 \\
\\
54.0\end{array}$ & $\begin{array}{l}44 \\
44 \\
34 \\
24\end{array}$ & $\begin{array}{r}88.0 \\
88.0 \\
68.0 \\
48.0 \\
74.0\end{array}$ & $0.000^{*}$ \\
\hline $\begin{array}{l}\text { The risky behaviors at work place: } \\
\text { - No eating food } \\
\text { - No drinking beverages } \\
\text { - No storing food ,drinks and cosmetics }\end{array}$ & $\begin{array}{l}50 \\
15 \\
0\end{array}$ & $\begin{array}{r}100.0 \\
30.0 \\
0.0\end{array}$ & $\begin{array}{l}50 \\
49 \\
45\end{array}$ & $\begin{array}{r}100.0 \\
98.0 \\
90.0\end{array}$ & $0.000^{*}$ \\
\hline $\begin{array}{l}\text { The risky practice at work place: } \\
\text { - Not handling contaminated material } \\
\text { - Not handling contaminated linens and } \\
\text { clothing } \\
\text { - Not handling contaminated wastes } \\
\text { - Not changing bed sheets. } \\
\text { - Not handling body fluids or body fluid- } \\
\text { contaminated clothing. }\end{array}$ & $\begin{array}{l}21 \\
5 \\
8\end{array}$ & $\begin{array}{l}74.0 \\
38.0 \\
42.0 \\
10.0 \\
16.0\end{array}$ & $\begin{array}{l}50 . \\
45 \\
37\end{array}$ & $\begin{array}{r}94.0 \\
100.0 \\
100.0 \\
90.0 \\
74.0\end{array}$ & $0.000 *$ \\
\hline
\end{tabular}

*: Statistically significant

This table shows that contaminated food and drink and handling materials contaminated with patients' excreta are considered the lowest mode of exposure as reported by studied nurses (2.0 $\%, 8.0 \%)$ respectively before intervention. The most common risky behavior according to nurses knowledge in pretest is eating food in handling area $(100.0 \%)$ while none of them $(0.0 \%)$ reported the storing food, drinks and cosmetics as risky behavior. The changing bed sheets and handling body fluid or fluid contaminated clothes are reported the least frequency by nurses at pretest $(10.0 \%, 16.0 \%)$ respectively. Finally, there is a statistically significant improvement of knowledge by health education. 
Table 3: Nurses practice regarding preparing, handling of cytotoxic drugs and use of Personal Protective Equipment (Gloves- Gowns - Eye protection) at pre and post intervention among studied nurses

\begin{tabular}{|c|c|c|c|c|c|}
\hline Aspect & & & & it test & P-value \\
\hline $\begin{array}{l}\text { Preparing \& Administrating CDs: } \\
\text { Improper place for preparing and handling } \\
\text { CDs. } \\
\text { Done } \\
\text { Not done } \\
\text { Expelling air from syringes filled with CDs. } \\
\text { Done } \\
\text { Not done } \\
\text { Contaminated hands and poor hand } \\
\text { washing. } \\
\text { Done } \\
\text { Not done } \\
\text { Generating aerosols during the } \\
\text { administration of drugs } \\
\text { Done } \\
\text { Not done } \\
\text { Counting uncoated oral tablets from multi- } \\
\text { dose bottles } \\
\text { Done } \\
\text { Not done }\end{array}$ & $\begin{array}{l}50 \\
0 \\
\\
50 \\
0 \\
\\
36 \\
14 \\
\\
50 \\
0 \\
\\
22 \\
28\end{array}$ & $\begin{array}{r}100.0 \\
0.0 \\
\\
100.0 \\
0.0 \\
\\
72.0 \\
28.0 \\
100.0 \\
0.0 \\
44.0 \\
56.0\end{array}$ & $\begin{array}{l}50 \\
0 \\
\\
37 \\
13 \\
\\
4\end{array}$ & $\begin{array}{r}100.0 \\
0.0 \\
74.0 \\
26.0 \\
8.0 \\
92.0 \\
80.0 \\
40.0 \\
6.00 \\
94.00\end{array}$ & $\begin{array}{l}0.000 * \\
0.000 *\end{array}$ \\
\hline $\begin{array}{l}\text { Handling CDs \& use of PPE } \\
\text { Handling contaminated linens and clothing } \\
\text { Done } \\
\text { Not done } \\
\text { Handling body fluids or body fluid- } \\
\text { contaminated clothing } \\
\text { Done } \\
\text { Not done } \\
\text { Use PPE when handling patients' waste } \\
\text { Done } \\
\text { Not done } \\
\text { Use PPE while cleaning up spills } \\
\text { Done } \\
\text { Not done }\end{array}$ & $\begin{array}{l}30 \\
20 \\
28 \\
22 \\
\\
17 \\
33 \\
\\
22 \\
28\end{array}$ & $\begin{array}{l}60.0 \\
40.0 \\
\\
56.0 \\
44.0 \\
\\
34.0 \\
66.0 \\
\\
44.0 \\
56.0\end{array}$ & $\begin{array}{l}12 \\
38 \\
\\
4 \\
46 \\
\\
49 \\
1 \\
\\
50 \\
0\end{array}$ & $\begin{array}{r}24.0 \\
76.0 \\
\\
8.0 \\
92.0 \\
\\
98.0 \\
2.0 \\
\\
100.0 \\
0.0\end{array}$ & $\begin{array}{l}0.000 * \\
0.000 *\end{array}$ \\
\hline
\end{tabular}

*: Statistically significant 
This table shows that the commonest risky nursing activities found regarding preparing CDs was improper place for preparing and handling CDs but it was the same before and after intervention, the least risky activity was counting uncoated oral tablets from multi-dose bottles (44.0\%). The commonest risky behavior while handling CDs was not using PPE when handling patient's waste $(66.0 \%)$. There was statistically significant improvement in studied nurses' practice after intervention regarding preparing and handling CDs.

\section{Table 4: Frequency of change of total knowledge and total performance after intervention among studied nurses}

\begin{tabular}{|l|cc|cc|c|}
\hline \multirow{2}{*}{ Item } & \multicolumn{2}{|c|}{ Pre test } & \multicolumn{2}{c|}{ Post test } & P-value \\
& No. & $\%$ & No. & $\%$ & \\
\hline Total knowledge & & & & & \\
Inadequate & 48 & 96.0 & 1 & 2.0 & $0.000^{*}$ \\
Adequate & 2 & 4.0 & 49 & 98.0 & \\
\hline Total performance & & & & & \\
Incorrect & 48 & 96.0 & 22 & 44.0 & $0.000^{*}$ \\
Correct & 2 & 4.0 & 28 & 56.0 & \\
\hline
\end{tabular}

*: Statistically significant

This table shows that there were a statistical significant improvement of total knowledge and performance after intervention by health education.

Measuring the correlation between change of knowledge and change of performance, results showed positive significant correlation $(\mathrm{r}=0.31$, P-value $=0.03)$ as knowledge increases, performance increases. 
Table 5: The effect of some socio-demographic and occupational data on change of knowledge and performance among studied nurses.

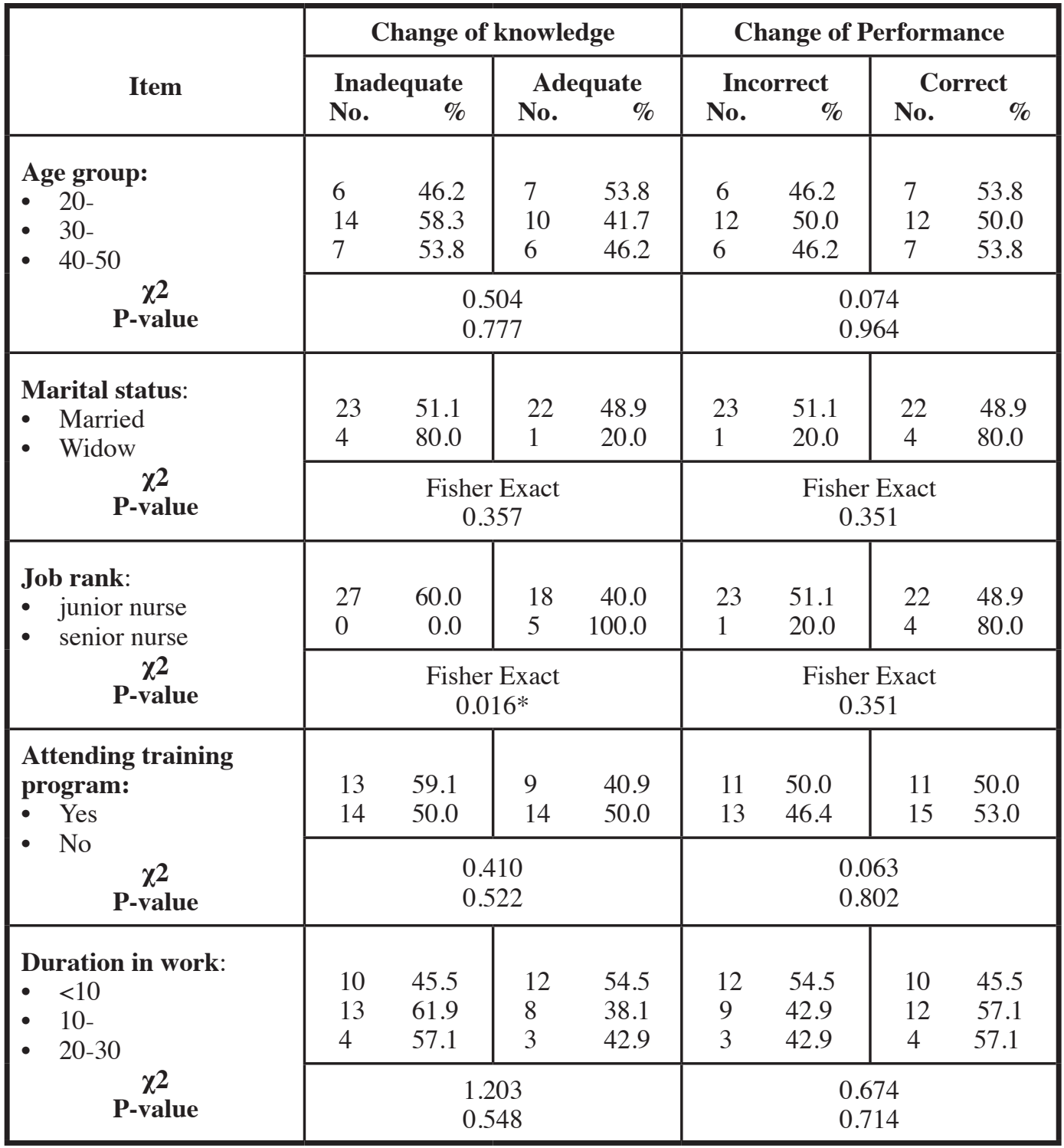

$* \mathrm{P}<0.05$ Significant

Table 5 showed that nearly all socio-demographic data didn't significantly affect change of knowledge and performance, except nurses job rank as the knowledge of senior nurses improved more than the knowledge of junior nurses. 


\section{Discussion}

This interventional study was conducted on 50 nurses exposed to CDs in oncology units at Zagazig university hospitals during the period from June 2014 to December 2014. (74.0\%) of the studied nurses are above 30 years and $(90.0 \%)$ are married, $(44.0 \%)$ of the studied nurses work in the oncology unit for less than 10 years (Table 1).

The results of the present work showed that nearly all of them don't attend training courses related to CDs handling. Only twelve percent $(12.0 \%)$ of the studied nurses mentioned that there is nursing care standard guideline for procedures for CDs. Only two percent $(2.0 \%)$ of the studied nurses reported that there is presence of inservice training programs (Table 1). They explained that by absence of any training courses related to CDs. Study results were in agreement with a previous studies which reported that few nurses attended training programs about occupational health and safety and even fewer mentioned that there are nursing care guidelines for procedures for dealing with patients receiving CDs as well as presence of in-service training programs (Elshamy et al., 2010; Chaudhary and Karn, 2012).
Our study was also consistent with previous studies which reported that their hospital had fewer nurses $(9.4 \%)$ receiving formal post-registration training on CDs compared with UK (96\%), Cyprus (18.2\%) and Pakistani (37.0\%) hospitals, in addition, none of them received pre-registration training (Verity et al., 2008 ; Kyprianou et al., 2010 ; Khan et al., 2012).

As Zagazig university hospitals continuously plan for infection control training course, more than forty percent $(44.0 \%)$ of studied nurses reported attending to this program (Table 1).

The findings of this work showed that the working place was not a safe environment, nurses reported that working environment had no proper preparation cabins. More than seventy percent $(72.0 \%)$ of the nurses reported that they prepare the CDs in treatment room (Table 1). This is because in our hospitals there is no specific pharmacy for preparing CDs.

Although, some of previous studies report similar finding (Chaudhary and Karn, 2012), other studies specially in developed countries reported that their working environment had aspiration system (Turk et al., 2004) and others were preparing CDs in laminar air flow 
(Martin and Larson, 2003). Finally, the use of proper preparation cabins has increased dramatically since 1997 (Kubilay et al., 1997). However, this is not the case in hospitals of developing countries like Egypt.

Anti neoplastic drugs are known to have adverse health effects among nurses. The findings indicate a higher frequency of several health hazards among studied nurses with high percent of reproductive hazards (Figure 1). This high percent is explained by the fact that all studied nurses are working in oncology unit since they were graduated and married during this period. Even if some of them had travelled or took any vacation due to any cause, when they returned to work; they worked in the same department.

This agrees with studies previously identified the effect of occupational exposure to CDs among nurses on reproductive outcomes (Pethran et al., 2003; Elshamy et al., 2010). A study by Martin, 2005 also documented learning disabilities in the children of nurses who had handled antineoplastic drugs during the course of their employment. Other studies reported a statistically significant association between fetal loss and occupational exposure to antineoplastic drugs during the first trimester of pregnancy (odds ratio 2.30, 95\% confidence interval 1.20-4.39) (Selevan et al., 1985; NIOSH, 2004).

The level of knowledge of the nurses about CDs is not satisfactory (Table 2). This is due to lack of training courses related to CDs handling .The results of the present work showed that there is highly significant improvement in studied nurses' knowledge after intervention regarding definition of CDs, mood of exposure, risky behavior and handling contaminated materials.

In accordance with our results, Habib and karam, 1992, Chaudhary and Karn, 2011 reported that the staff handling the CDs don't have a satisfactory level of knowledge regarding the risk factors. This lack of knowledge on preventive measures is of concern because it increases the health workers' risky behavior.

Also results were consistent with other studies, (Turk et al., 2004; Kyprianou et al., 2010; Polovich and Clark, 2010; Keat et al., 2013) which reported that there was a significant improvement of knowledge levels among the nurses on cytotoxic drug handling after educational training program. 
Concerning nurses performance, improper place for preparing and handling CDs, generating aerosols during the administration of drugs and expelling air from syringes are the commonest risky nursing activity representing (100.0\%). The least risky nursing activity is counting uncoated oral tablets from multi-dose bottles $(44.0 \%)$, this is because most nurses give oral tablets to the relatives to give them to the patients (Table 3).

Study results are in agreement with a previous study conducted by Elshamy et al., 2010 who reported that improper place for preparing and handling CDs as well as expelling air from syringes filled with CDs were common risky nursing activities. This was due to the fact that although the primary function of the oncology nurse is to administer the drugs, in some instances drugs may also be prepared at this site due to absence of clinical pharmacy facilities.

Our results showed that there is significant improvement in studied nurses' practice after intervention regarding the use of personal protective equipment during handling patients' waste and cleaning up spills (Table 3). They use them poorly before intervention because they don't know that contact with patient waste and cleaning up spills can expose them to hazards of CDs and there is not enough gloves to wear it.

Results of the study are in accordance with other studies (Turk et al. 2004 ; Elshamy et al., 2010 ; Chaudhary and Karn, 2012 ; Shrestha, 2012) which reported that there was poor use of gloves, gowns and personal protective equipment by study nurses when handling patient waste, and when cleaning up spills. In contrast, a previous study of Oncology Nursing Society in Turkey (Kubilay et al., 1997) reported that the use of working suit and goggles continue to be limited even after intervention.

The results of the present work showed that there is highly significant improvement in studied nurses' total knowledge and total performance after intervention (Table 4). Also the results of the present work showed that there is positive significant correlation between change of knowledge and change of practice, as knowledge improved, practice improved.

Participating in a health education program created significant difference on the level of knowledge and changing the practice of participating nurses; the 
training of nurses involved with any aspect of the handling of hazardous drugs is essential for their safety.

This is in agreement with previous studies (Turk et al., 2004; Khan et al., 2012; Yuan et al., 2012) which reported that the findings of nurses' knowledge assessment reflect the effectiveness of education and training which has been claimed as a useful tool to improve the nurses' knowledge on cytotoxic drug handling.

Polovich and Clark, 2010 and Khan et al., 2012 reported that high knowledge levels among the nurses are important to improve their adherence to the safety measures and to elevate their sense of well-being.

Finding were also consistent with other studies (Turk et al. 2004; Polovich and Clark, 2010) which reported a positive relationship between the nurses' perceived risk of harms from hazardous drug exposure and the application of safety measures, they also reported that an improved safety climate in workplace was proven to be associated with the nurses' self-efficacy of precaution use.

In contrast with our study results, Chaudhary and Karn, 2012 reported that no significant differences were found in the mean scores of knowledge regarding $\mathrm{CDs}$, and frequency of risky behaviors in working environment.

In our study, the sociodemographic characteristics have no role in improvement of knowledge nor practice (Table 5). This is because none of them despite their differences, receive any training courses related to CDs. The position of nurses only affect their knowledge. This is due to differences in education which makes senior nurses more keen to be aware of all aspects regarding CDs handling.

In agreement with our results, a study by Fahimi et al. 2008 found no significant relationship between the rate of errors and the age of nurses, their gender, years of nursing experience and marital status.

\section{Conclusion and Recommendations}

It was clear from this study that the level of knowledge of the nurses about cytotoxic drugs (CDs) is not satisfactory. Awareness of the nurses handling the CDs is of concern because it is important in raising the standards of safety. It was also concluded that sufficient education and training as well as hospital policy are effective tools to improve the 
safety climate in hospitals providing CDs actively. So we recommend an integrated health monitoring program that includes the assessment and counseling of prospective nurses before they commence any work involving CDs. In-service training, improvement of the work environment, good planning and design of the workplace and supplying protective equipment is also important. A safety committee in the hospital should ensure the appropriate implementation of safety policies, and keep the staff informed about the procedures for safety handling of CDs

\section{Conflict of interests}

Authors have declared that no conflict of interests exists.

\section{References}

1. Ahmad A (2001): Managing cytotoxic drugs. Malaysian J Pharm; 1:63-71.

2. Chaudhary R and Karn K (2012): CDsKnowledge and Handling Practice of Nurses Working in a Medical University of Nepal. Journal of Cancer Therapy; 3:110-114. Available online from: http://www.SciRP.org/ journal/jet

3. Elshamy K, El-Hadidi M, El-Roby M and Fouda M (2010): Health Hazards among Oncology Nurses Exposed to CDs Drugs. Afr J Haematol Oncol; 1(3):70-78.

4. Fahimi F, Ariapanah P, Faizi M, Shafaghi B, Namdar R and Ardakani M (2008): Errors in preparation and administration of intravenous medications in the intensive care unit of a teaching hospital: an observational study. Aust Crit Care; 21:110-116.
5. Habib C and Karam S (1992): Handling of Antineoplastic Pro- ducts and Nurses' Knowledge. Le Journal Medical Li- banais; 40(4): 182-186.

6. Keat C, Sooaid N, Yun C and Srirama M (2013): Improving Safety-Related Knowledge, Attitude and Practices of Nurses Handling Cytotoxic Anticancer Drug: Pharmacists' Experience in a General Hospital, Malaysia. Asian Pacific Journal of Cancer Prevention; 14:69-73.

7. Khan N, Khowaja K and Ali T (2012): Assessment of knowledge, skill and attitude of nurses in CDs administration in tertiary hospital Pakistan. Open J Nursing; 2:97-103.

8. Kubilay G, Fesci H and Erdem Y (1997): Evaluation of the status of the nurses preparing and administrating CDs. Oncology Nurses' Association; 6:7-15.

9. Kyprianou M, Kapsou M and Raftopoulos V (2010): Knowledge, attitudes and beliefs of Cypriot nurses on the handling of antineoplastic agents. Eur J Oncol Nur; 14:278-360.

10. Martin S (2005): CDs handling and effects among nurses and their offspring. Paper presented at: the Oncology Nursing Society 30th Annual Congress; Orlando, Florida USA. Abstract 13.

11. Martin S and Larson E (2003): CDs handling practices of outpatient and office-based oncology nurses. Oncology Nursing Forum; 30:575-81.

12. Meijster $\mathrm{T}$, Fransman $\mathrm{W}$, Veldhof $\mathrm{R}$ and Kromhout H (2006): Exposure to Antineoplastic Drugs outside the Hospital Environment. Ann Occup Hyg; 50:657-664.

13. NIOSH (National Institute for Occupational Safety and Health) (2004): NIOSH Alert Preventing Occupational Exposure to Antineoplastic and Other Hazardous Drugs in Health Care Settings-165. Available online from: http://www.cdc.gov/niosh/docs/2004165.

14. Pethran A, Schierl R, Hauff K, Grimm C, Boos K and Nowak D. (2003): Uptake of antineoplastic 
agents in pharmacy and hospital personnel. Part 1: monitoring of urinary concentrations. Int Arch Occup Environ Health; 76:5-10.

15. Polovich M and Clark P (2010): Nurses' Use of Hazardous Drug Safe Handling Precautions. Unpublished study. Georgia State University. Available online from: https://www2.ons.org/ CNECentral/Conferences/Congress/2011/learn/ media/ons/docs/conferences/congress/2011/ saturdaysundaysyllabus.pdf

16. Schreiber C, Radon K, Pethran A, Schierl R, Hauff K, Grimm C, Boos K and Nowak D (2002): Uptake of antineoplastic agents in pharmacy personnel. Part II: study of work related risk factors. Int Arch Occup Environ Health; 76(1):11-6.

17. Selevan S, Lindbohm M, Hornung $R$ and Hemminki K (1985): A study of occupational exposure to antineoplastic drugs and fetal loss in nurses. NEJM; 313(19):1173- 1178.

18. Shrestha J (2012): A Study to Assess the Effectiveness of Structured Teaching Program on Knowledge Regarding Safe Handling and
Administration of Cytotoxic Drugs among Nurses in Selected Hospital, BANGALORE. Available online at: http://www.rguhs.ac.in/ cdc/onlinecdc/uploads/05_N134_40726.doc.

19. Thomas DA, Sarris AH, Cortes J, Faderl S, O’Brien S, Giles F, Garcia-Manero G, Rodriguez M, Cabanillas F and Kantarjian H (2006): Phase II study of sphingosomal vincristine in patients with recurrent or refractory adult acute lymphocytic leukemia. Cancer; 106:120-127.

20. Turk M, Davas A and Ciceklioglu M (2004): Knowledge, attitude and safety behaviour of nurses in handling cytotoxic anticancer drugs in Ege University Hospital. Asian Pac J Cancer Prev; 5:164-172.

21. Verity R, Wiseman $T$ and Ream, (2008): Exploring the work of nurses who administer CDs. Euro J Oncol Nursing; 123:244-52.

22. Yuan Y, Xu D and Wang B (2012): An investigation into the occupational protection status of clinical nursing staff exposed to antitumor drugs. J Med Colleges PLA;27:11312. 